\title{
The impact of virtual rotation on student engagement and performance.
}

\author{
Peter J. Draus, Robert Morris University, draus@rmu.edu
}

\begin{abstract}
This research looks at a section of Python programming that was offered using Virtual Rotation. Students rotated between synchronous online and in -person learning environments. Overall performance in the class was compared against previous synchronous online and in-person classes. A X2 analysis found no difference in overall performance between the group whereas previous researchers had found positive improvements in a Blended learning environment. A count of early and late submissions for the homework was also analyzed using X2. This variable was used as a proxy for student engagement. Differences were found between students when they were in their virtual week as opposed to the same students when they were in their in-person week. This lateness of submissions was found when comparing homework submission from previous years as well. Suggestions are made for future research.
\end{abstract}

Keywords: Information Technology (IT), Blended Learning, Rotational Model, Cognitive Theory of Multimedia Learning

\section{Introduction}

The global pandemic has impacted all aspects of life including teaching and learning. These changes have resulted in vast amounts of instruction moving online (Kahn et al, 2020). In addition to straight online instruction has utilized a more blended approach. This blended environment involves multiple instructional environments and modalities. (Mohammed Abdel-Haq (2021). As we all struggled to keep teaching during the changing times the definitions and boundaries of the environments kept changing. An interesting aspect of this change was not just the speed and scope of the change, but that the driving force did not come from any of the constitutes. Neither student, teachers, administrator, or society was pushing for the utilization of these new teaching environments. (Ben, F. 2020)

After making the initial change to accommodate the sudden changed environment, researchers are now looking to evaluation the different methods and the effectiveness of these methods on different population and in different environments. The impact of the new instructional design also impacted student satisfaction and engagement. (Caskurlu, et al, 2020) One area that many focused on was the use of a blended teaching environment. There is evidence that the discipline of the student/topics impact both effectiveness and student satisfaction. (Vo, Zhu \& Diep, 2020)

\section{Literature Review}

Pervious research has shown gender difference to student satisfaction to online learning. (Rovai \& Barnum, 2007) Some more recent research has shown not only differences in satisfaction but performance in blended environments based on gender. (Polhun, et al, 2021) Another researcher found that female students not only had a higher overall course grades but earned more extra credits points. (Volchok 2018) Other researchers 


\section{Issues in Information Systems}

Volume 22, Issue 2, pp. 276-284, 2021

found no difference in overall performance by gender but did find differences in overall satisfaction with the learning environment. Lee \& Hung (2015). Clearly there and many different variables that need to be addressed before these new instructional strategies can be employed in the most efficient manner.

\section{Blended Learning and the Rotational Model}

A blended learning environment, while not widespread, was being used years before the pandemic arrived. (Dakhi, Jama \& Irfan,2020) also describe the blended environment as using multiple instructional environments. Blended learning is a model of instruction that utilizes multiple learning environments that students rotate through depending on the content and learning activities for that session. A similar definition is used by multiple instructors and researchers. (Mohammed Abdel-Haq 2021). Horn \& Staker, H. (2017) go further and require the online component to be asynchronous to allow the student more control of the learning environment. They also discuss the rotation model and emphasize the rotation to different "stations" or learning environments is due to different learning activities or material for each group, not just for convenience or logistical necessity.

Ayob, et al (2020) found improved performance in a blended environment as long as it included more than just in person and online instruction. Other researchers also found improved performance as well as lower student dropout rate and higher student satisfaction. (Deperlioglu \& Kose 2013).

When looking at improved performance, Luo \& Wang (2020) looked beyond the learning environment but looked at the level of interaction and level of student preparedness. They found little difference when using a blended environment with "Excellent" and "Moderate" students, but found three groups of students in the poor performance category, some with excellent online interaction, some who spent long time periods online, but still did poorly and others who just never clicked on the video. Draus, P. (2020) also found distinct groupings of students based on how they interact with the videos in an asynchronous online environment with no discernable difference in performance.

It is important to note that blended learning implies more than just the same instruction given in a different modality, Cronje (2020) stresses the importance of utilizing instructional design to maximize benefits for the different modalities. Moskal, Dziuban \& Hartman (2013) state that for blended learning to be effective the entire school environment must support and encourage its effectiveness. They found lower withdrawal rates were part of this holistic approach to blended learning.

\section{Virtual Rotation}

Virtual Rotation is an instructional Strategy where a single classroom sized group of students is split into 2 or 3 groups. The groups then rotate one in the classroom and one or two attending synchronously online. (Robert Morris University, 2021,4,12) This was implemented due to the pandemic and is designed to allow for social distancing without reducing class size. This method would not be considered blended for most researchers as it only used in person and online and rotates simply by time and not by content using multiple instructional environments. (Polhun, et al, 2021)

\section{Cognitive Load Theory}

Sweller $(1988,2005)$ developed the Cognitive Load Theory from the principles of the human cognitive model of information processing. The theory proposes that there are three different loads that the people need to process when learning new information. First there is the Intrinsic load, which is how many connections the new material must be made to existing knowledge to be useful. Germane load is second and relates to the amount of effort needed to make those connections at the desired criterion level. The last 


\section{Issues in Information Systems}

Volume 22, Issue 2, pp. 276-284, 2021

load is the Extraneous load. This load is defined as how much cognitive effort is required to obtain the Germane load from the information received. This theory was then refined into the Cognitive Theory of Multimedia Learning.

\section{Cognitive Theory of Multimedia Learning}

The Cognitive Theory of Multimedia Learning was developed by Mayer (2002) and states that two channels of input, audio and visual combined can increase cognitive throughput. There is a limiting factor in that if either channel is overloaded the negative aspects impact both channel throughput. Some design considerations that utilize this theory were highlighted by Brame $(2015,2016)$ include 1) Signaling or cueing such as using highlighting, pointers and adding text which will reduce extraneous load 2) Segmenting or chunking of info which reduces overall intrinsic load and 3) Weeding or removing distracting detail which reduces extraneous load and 4) Matching modality - use the audio or visual mode that is most effective at reducing cognitive load.

Gates (1995)

\section{Student Engagement and Teaching Presence}

Teaching presence is always a key design feature for the online environment. A meta-analysis by Caskurlu et al. (2020) found that increased teacher presence resulted in increased student satisfaction, but only a moderate impact on student outcomes. Draus \& Curren (2014) found that the inclusion of online videos didn't improve performance but did increase student satisfaction. Park and Kim (2020) linked student satisfaction to both actions that lead to students increasing the "Task Value" but also to their "Learning Flow" which is their willingness to engage in actions to complete the objectives. The worry in a Virtual Rotation environment is that the level of "Learning flow" is diminished as measured by the time to complete a homework assignment.

The goal of this research is to determine the impact of the virtual rotation model on student engagement and performance in learning a programming language and to look at the results utilizing the Cognitive Theory of Multimedia learning in the evaluation. Tadlaoui \& Chekour (2021) have already set the groundwork by demonstrating positive results in teaching Python programming using a blended method.

\section{Methodology}

An introductory Python programming course that has been taught both on ground and online was scheduled to include Virtual Rotation. The researcher was interested in how the level of student performance and the level of student engagement might be impacted by this new instructional format.

Two research questions were developed.

RQ1: What was the impact of Virtual Rotation on student engagement in an introductory Python programming class?

RQ2: What was the impact of Virtual Rotation on student performance in an introductory Python programming class?

Student engagement was measured for each homework assignment if the assignment was turned in 'early' or 'on time/late'. When the course is taught on ground most students turn in their homework the same night it is passed out or 1 day later. The course meets for a 4-hour time period with the last 90 minutes 


\section{Issues in Information Systems}

Volume 22, Issue 2, pp. 276-284, 2021

spent in the lab working on the assignment. Even in the Virtual Rotation, students were expected to be working on their assignment while the instructor was present to provide assistance. In the online course section, students usually turn in their assignments within a day or two of starting work on the material. Each week the material is opened on Friday and the homework is due the following Saturday. For this research "Early" was considered by Monday at Midnight for the asynchronous online sections.

To look for differences between the in-class group and the Virtual group, a X2 test was used. The same test was used to look for difference in overall performance between the Virtual Rotation section and both the online and in person sections from previous years.

\section{Results}

20 students registered for the Python class and were randomly assigned to two Virtual Rotation groups. Each week one group would meet in the classroom while that other group attended the class virtually using a synchronous modality. Full two-way communication between the virtual students and the instructor and class was maintained throughout the class. Since this was partially a lab session, virtual students would share their screen with the instructor when they needed help.

In addition to the students in the Virtual Rotation class, data from 83 students from past in person classes and 45 students from past online classes was gathered for comparison.

RQ1: What was the impact of Virtual Rotation on student engagement in an introductory Python programming class?

A $X^{2}$ was used to compare submissions between students in the virtual environment and those in the inperson environment. Since students switched each week, the results should balance out for any confounding variables for each student. Data was gathered for the 4 homework assignments. The results, as shown in Table 1, indicate a significant difference $\left(X^{2}(1, \mathrm{~N}=79)=11.933, \mathrm{p}=.000551\right)$ between the virtual group and the in-person group. The in-person group turning in their assignments early and the virtual students turning them in on the due date or late.

Table 1 Counts of Overall Homework submissions

\begin{tabular}{|l|c|c|}
\hline & In Class & $\begin{array}{c}\text { Synchronous } \\
\text { Online/VR }\end{array}$ \\
\hline $\begin{array}{l}\text { Early } \\
\text { submission }\end{array}$ & 22 & 9 \\
\hline Late submission & 15 & 33 \\
\hline
\end{tabular}

Each individual homework assignment was also tested. The results are listed in Tables 2-5 below. Homework's 1,2 and 4 showed no significance differences in the $X^{2}$ results with Homework \#3 having significant $\left(X^{2}(1, \mathrm{~N}=20)=3.90, \mathrm{p}=.048\right)$ differences between the students who were in person and the students who were virtual and attending class synchronously online.

Table 2 Counts of Homework 1 submissions

\begin{tabular}{|l|c|c|}
\hline & In Class & $\begin{array}{c}\text { Synchronous } \\
\text { Online/VR }\end{array}$ \\
\hline $\begin{array}{l}\text { Early } \\
\text { submission }\end{array}$ & 4 & 1 \\
\hline Late submission & 6 & 9 \\
\hline
\end{tabular}


Homework \#1 was a simple Python program demonstrating looping and lists. Results (Table 2 ) indicated no difference between in person and VR groups in the timeliness of their submission. $\left(X^{2}(1, \mathrm{~N}=20)=2.4\right.$, $\mathrm{p}=.12)$

Table 3 Counts of Homework 2submissions

\begin{tabular}{|l|c|c|}
\hline & In Class & $\begin{array}{c}\text { Synchronous } \\
\text { Online/VR }\end{array}$ \\
\hline $\begin{array}{l}\text { Early } \\
\text { submission }\end{array}$ & 8 & 4 \\
\hline Late submission & 2 & 6 \\
\hline
\end{tabular}

Homework \#2 was a simple Python program demonstrating three different graphs using matplotlib. Results (Table 3) indicated no difference between in person and VR groups in the timeliness of their submission. $\left(X^{2}(1, \mathrm{~N}=20)=3.33, \mathrm{p}=.067\right)$

Table 4 Counts of Homework 3 submissions

\begin{tabular}{|l|c|c|}
\hline & In Class & $\begin{array}{c}\text { Synchronous } \\
\text { Online/VR }\end{array}$ \\
\hline $\begin{array}{l}\text { Early } \\
\text { submission }\end{array}$ & 5 & 2 \\
\hline Late submission & 3 & 9 \\
\hline
\end{tabular}

Homework \#3 was a simple program demonstrating user interaction, random numbers and multiple list manipulation. Results (Table 4) indicated that there were significance differences between in person and VR groups in the timeliness of their submission. $\left(X^{2}(1, \mathrm{~N}=19)=3.90, \mathrm{p}=.048\right)$

Table 5 Counts of Homework 4 submissions

\begin{tabular}{|l|c|c|}
\hline & In Class & $\begin{array}{c}\text { Synchronous } \\
\text { Online/VR }\end{array}$ \\
\hline $\begin{array}{l}\text { Early } \\
\text { submission }\end{array}$ & 5 & 2 \\
\hline Late submission & 4 & 9 \\
\hline
\end{tabular}

Homework \#4 was a more complex Python program asking students to read in a large CSV file, group some rows and calculate values to plot using matplotlib. Results (Table 5) indicated no difference between in person and VR groups in the timeliness of their submission. $\left(X^{2}(1, \mathrm{~N}=20)=3.09, \mathrm{p}=.08\right)$

Comparing the results to previous terms sections, both asynchronous online and in person, yielded interesting results. Table 6 shows the submission information for the three teaching environments. A $X^{2}$ test $\left(X^{2}(2, \mathrm{~N}=591)=18.491, \mathrm{p}=.000097\right)$ showed that the Synchronous Online/VR group was significantly different than the other two groups. Further analysis showed no differences between the asynchronous online and on ground groups. 
Table 6 Submission Timeliness for Different teaching Modalities

\begin{tabular}{|l|l|l|l|}
\hline & In Class & \multicolumn{1}{|c|}{$\begin{array}{c}\text { Asynchronous } \\
\text { Online }\end{array}$} & $\begin{array}{l}\text { Synchronous } \\
\text { Online/VR }\end{array}$ \\
\hline $\begin{array}{l}\text { Early } \\
\text { submission }\end{array}$ & 196 & 122 & 31 \\
\hline $\begin{array}{l}\text { Late } \\
\text { submission }\end{array}$ & 136 & 58 & 48 \\
\hline
\end{tabular}

It should be noted that all three groups were given access to the asynchronous online material as part of their course. This means that the VR modality actual impacted students negatively in terms of their turning in their assignments early.

RQ2: What was the impact of Virtual Rotation on student performance in an introductory Python programming class?

Since all students in the Virtual Rotation class received both in person and synchronous online instruction a comparison of final grade within that class cannot be completed. Final grades for all previous sections, both in person and asynchronous online were tabulated. There has been a negative impact on student engagement as a result of Virtual Rotation, but a look at overall performance showed students performed similarly across all three modalities, as can be seen in Table 7 below.

Table 7 Submission Timeliness for Different teaching Modalities

\begin{tabular}{|l|l|l|l|}
\hline Grade & $\begin{array}{c}\text { In } \\
\text { Person }\end{array}$ & $\begin{array}{c}\text { Asynchronous } \\
\text { Online }\end{array}$ & $\begin{array}{l}\text { Synchronous } \\
\text { Online/VR }\end{array}$ \\
\hline A & $\begin{array}{l}65 \\
(78 \%)\end{array}$ & $33(73 \%)$ & $12(60 \%)$ \\
\hline B & $\begin{array}{l}13 \\
(16 \%)\end{array}$ & $7(16 \%)$ & $6(30 \%)$ \\
\hline C & $2(2 \%)$ & $2(4 \%)$ & 0 \\
\hline D & $1(1 \%)$ & $2(4 \%)$ & 0 \\
\hline F & $2(2)$ & $1(2 \%)$ & $2(10 \%)$ \\
\hline
\end{tabular}

To complete a $X^{2}$ test without having empty cells, the last three rows of Table 1 were collapsed together. The results indicated there were no significant differences between the final course grades and the method of instruction. There were two degrees of freedom with a sample size of 148. The Chi-square statistic value was 3.80 with a significance of .433 .

As part of the course evaluation, students in the Virtual Rotation class $(\mathrm{N}=20)$ were asked if they prefer to have the instruction in person. Only 11 students responded to that question. They had a 5-point Likerttype scale (Strongly Disagree, Disagree, Neither Agree, Strongly Agree) to pick from for their answer. Only 1 person selected "Disagree" implying that they did not want in person instruction. 6 students selected "Agree" or "Strongly" agree with the remaining 4 selecting "Neither." Clearly the students in the class who chose to respond preferred in class instruction. This might have impacted the results for this course. The Virtual Rotation course was the only option that semester and students did not have the option of online or in person. 


\section{Issues in Information Systems}

Volume 22, Issue 2, pp. 276-284, 2021

\section{Discussion}

Data from 4 homework assignments from a Virtual Rotation course was compared week to week for student engagement using early submission as a proxy for engagement. The first research question, "What was the impact of Virtual Rotation on student engagement in an introductory Python programming class?" showed that overall students turned in their assignments early for the weeks they were in the on-ground course significantly more often. Of the four homework's measured, only one showed an individual difference. This could be due to the very small size of the sample.

Data from the past 3 years was used to compare final grades for the students to answer research question 2. "What was the impact of Virtual Rotation on student performance in an introductory Python programming class?" There were no differences in the distribution of final grades between any of the three teaching methods, in person, asynchronous online and synchronous Virtual Rotation.

These results support that the benefits of blended learning do not follow in a Virtual Rotation environment and that the inclusion of synchronous videos as well as the synchronous videos in the online environment may have overloaded the processing channels as defined by the Cognitive Theory of Multimedia Learning. It appears that the need for the student to pay attention to the videos and the example programs on the same input modality (The computer screen) leads to cognitive overload.

Virtual Rotation is a system of switching between in class and synchronous online instruction for each class session. While it is similar to the rotational model of blended learning, it does not meet all of the criteria. The results did not show the generally positive results from utilizing the rotational model in blended learning but did not have any negative impact of overall performance.

The students who were online did turn in their assignments later than those students who were on ground and looking at previous data, turned in their assignments later than those students in a total on ground class and a total asynchronous online class. This suggests a lack of engagement in the course. The cognitive theory of multimedia learning suggests a possible reason for this in that the availability of the asynchronous video, even though it was not part of the class experience may have contributed to an overload of the information processing channels and lead to the delay in turning in the assignments.

Due to the small sample size for the Virtual Rotation class, further data needs to be gathered. Additionally, due to the lack of options, students could not choose their preferred teaching method when registering for the course. Hopefully this variable can be taken into account in future research. Finally removing the option to view the asynchronous video material from the Virtual Rotation sections might improve performance. This option should also be explored.

\section{References}

Ayob, N. F. S., Abd Halim, N. D., Zulkifli, N. N., Zaid, N. M., \& Mokhtar, M. (2020). Overview of blended learning: The effect of station rotation model on students $\{'\}$ achievement. Journal of Critical Reviews, 7(6), 320-326.

Ben, F. (2020, December). Forced into it: Digital Technologies for Teaching and Learning During a Global Pandemic. In 1st International Conference on Information Technology and Education (ICITE 2020) (pp. 588-592). Atlantis Press.

Brame, C. J. (2015). Effective educational videos. Vanderbilt University Center for Teaching. 


\section{Issues in Information Systems}

Volume 22, Issue 2, pp. 276-284, 2021

Brame, C. J. (2016). Effective educational videos: Principles and guidelines for maximizing student learning from video content. CBE—Life Sciences Education, 15(4), es6.

Caskurlu, S., Maeda, Y., Richardson, J. C., \& Lv, J. (2020). A meta-analysis addressing the relationship between teaching presence and students' satisfaction and learning. Computers \& Education, 157, 103966.

Cronje, J. (2020). Towards a New Definition of Blended Learning. Electronic Journal of e-Learning, 18(2), pp114-121.

DAKHI, O., JAMA, J., \& IRFAN, D. (2020). Blended Learning: A 21st Century Learning Model At College. International Journal Of Multi Science, 1(08), 50-65.

Deperlioglu, O., \& Kose, U. (2013). The effectiveness and experiences of blended learning approaches to computer programming education. Computer Applications in Engineering Education, 21(2), 328342 .

Draus, P. J., Curran, M. J., \& Trempus, M. S. (2014). The influence of instructor-generated video content on student satisfaction with and engagement in asynchronous online classes. Journal of Online Learning and Teaching, 10(2), 240-254.

Draus, P. (2020). Impact Of Student Engagement Strategies On Video Content In Learning Computer Programming And Attitudes Towards Video Instruction That Was Developed Based On The Cognitive Theory Of Multimedia Learning. Issues in Information Systems, 21(3).

Horn, M. B., \& Staker, H. (2017). Blended: Using disruptive innovation to improve schools. John Wiley \& Sons.

Khan, S., Rabbani, R. M., Thalassinos, I. E., \& Atif, M. (2020). Corona virus pandemic paving ways to next generation of learning and teaching: Futuristic cloud based educational model. Available at SSRN 3669832.

Lee, L. T., \& Hung, J. C. (2015). Effects of blended e-Learning: a case study in higher education tax learning setting. Human-centric Computing and Information Sciences, 5(1), 1-15.

Luo, J., \& Wang, T. (2020, September). Analyzing Students' Behavior in Blended Learning Environment for Programming Education. In Proceedings of the 2020 The 2nd World Symposium on Software Engineering (pp. 179-185).

Mohammed Abdel-Haq, E. (2021). The Blended Learning Model: Does It Work?. Sohag University International Journal of Educational Research, 3(3), 29-40.

Mayer, R. (Ed.). (2014). The Cambridge Handbook of Multimedia Learning (Cambridge Handbooks in Psychology). Cambridge: Cambridge University Press. doi:10.1017/CBO9781139547369

Moskal, P., Dziuban, C., \& Hartman, J. (2013). Blended learning: A dangerous idea?. The Internet and Higher Education, 18, 15-23. 


\section{Issues in Information Systems}

Volume 22, Issue 2, pp. 276-284, 2021

Park, J. Y., \& Kim, S. (2020). Analysis of Influencing Factors of Learning Engagement and Teaching Presence in Online Programming Classes. Journal of information and communication convergence engineering, 18(4), 239-244.

Polhun, K., Kramarenko, T., Maloivan, M., \& Tomilina, A. (2021, March). Shift from blended learning to distance one during the lockdown period using Moodle: test control of students' academic achievement and analysis of its results. In Journal of Physics: Conference Series (Vol. 1840, No. 1, p. 012053). IOP Publishing.

Robert Morris University, $(2021,4,12)$ Virtual Rotation. https://www.rmu.edu/academics/virtualrotation

Rovai, A. P., \& Barnum, K. T. (2007). On-line course effectiveness: An analysis of student interactions and perceptions of learning. International Journal of E-Learning \& Distance Education/Revue internationale du e-learning et la formation à distance, 18(1), 57-73.

Sweller, J. (1988). Cognitive load during problem solving: Effects on learning. Cognitive science, 12(2), 257-285.

Sweller, J. (2005). Implications of cognitive load theory for multimedia learning. The Cambridge handbook of multimedia learning, 3(2), 19-30

Tadlaoui, M. A., \& Chekour, M. (2021). A blended learning approach for teaching python programming language: towards a post pandemic pedagogy. International Journal of Advanced Computer Research, 11, 52.

Vo, M. H., Zhu, C., \& Diep, A. N. (2020). Students' performance in blended learning: disciplinary difference and instructional design factors. Journal of Computers in Education, 7(4), 487-510.

Volchok, E. (2018). Differences in the performance of male and female students in partially online courses at a community college. Community College Journal of Research and Practice. 